\title{
Consistent responses of soil microbial taxonomic and functional attributes to mercury pollution across China
}

\author{
Yu-Rong Liu' ${ }^{1,2,3^{*}}$ (D), Manuel Delgado-Baquerizo ${ }^{4,5}, \mathrm{Li} \mathrm{Bi}^{2}$, Jun Zhu ${ }^{3}$ and Ji-Zheng $\mathrm{He}^{2,6}$
}

\begin{abstract}
Background: The ecological consequences of mercury $(\mathrm{Hg})$ pollution—one of the major pollutants worldwide—on microbial taxonomic and functional attributes remain poorly understood and largely unexplored. Using soils from two typical Hg-impacted regions across China, here, we evaluated the role of $\mathrm{Hg}$ pollution in regulating bacterial abundance, diversity, and co-occurrence network. We also investigated the associations between $\mathrm{Hg}$ contents and the relative abundance of microbial functional genes by analyzing the soil metagenomes from a subset of those sites.

Results: We found that soil $\mathrm{Hg}$ largely influenced the taxonomic and functional attributes of microbial communities in the two studied regions. In general, Hg pollution was negatively related to bacterial abundance, but positively related to the diversity of bacteria in two separate regions. We also found some consistent associations between soil $\mathrm{Hg}$ contents and the community composition of bacteria. For example, soil total $\mathrm{Hg}$ content was positively related to the relative abundance of Firmicutes and Bacteroidetes in both paddy and upland soils. In contrast, the methylmercury (MeHg) concentration was negatively correlated to the relative abundance of Nitrospirae in the two types of soils. Increases in soil Hg pollution correlated with drastic changes in the relative abundance of ecological clusters within the co-occurrence network of bacterial communities for the two regions. Using metagenomic data, we were also able to detect the effect of $\mathrm{Hg}$ pollution on multiple functional genes relevant to key soil processes such as element cycles and $\mathrm{Hg}$ transformations (e.g., methylation and reduction).

Conclusions: Together, our study provides solid evidence that $\mathrm{Hg}$ pollution has predictable and significant effects on multiple taxonomic and functional attributes including bacterial abundance, diversity, and the relative abundance of ecological clusters and functional genes. Our results suggest an increase in soil Hg pollution linked to human activities will lead to predictable shifts in the taxonomic and functional attributes in the Hg-impacted areas, with potential implications for sustainable management of agricultural ecosystems and elsewhere.
\end{abstract}

Keywords: Soil microbial community, Co-occurrence network, Functional gene, Metagenomics, Mercury pollution

\section{Background}

Environmental pollution resulting from human activities has a great impact on the biodiversity and functioning of terrestrial and aquatic ecosystems and is a major threat for human health across the globe [1-4]. Importantly, recent studies suggested that changing climate

\footnotetext{
* Correspondence: yrliu@mail.hzau.edu.cn

${ }^{1}$ State Key Laboratory of Agricultural Microbiology, Huazhong Agricultural University, Wuhan 430070, People's Republic of China

${ }^{2}$ State Key Laboratory of Urban and Regional Ecology, Research Center for Eco-Environmental Sciences, Chinese Academy of Sciences, Beijing 100085, China

Full list of author information is available at the end of the article
}

exacerbates global mercury $(\mathrm{Hg})$ pollution by releasing historically stocked $\mathrm{Hg}$ in the permafrost $[5,6]$. Such a threat is of global concern as $\mathrm{Hg}$ can be transported globally [7]. The elevated $\mathrm{Hg}$ inputs into environments could have significant effects on soil biodiversity and their associated ecosystem functions $[8,9]$. Studies conducted at the local scale seemed to support the idea that $\mathrm{Hg}$ pollution can alter soil microbial communities [1012]. Moreover, previous work based on short-term incubation experiments demonstrated that $\mathrm{Hg}$ amendments can alter the soil microbiome and its ecological functions $[13,14]$. However, much less is known on the role of $\mathrm{Hg}$ pollution in shaping the taxonomic and functional 
attributes of microbial communities in natural ecosystems across large spatial scale and different types of croplands.

Recent studies suggested that microbial taxa strongly co-occur within ecological network that often are called ecological clusters or modules $[15,16]$. Such ecological clusters are expected to have multiple implications for the maintenance of soil fertility, decomposition, and ecological services in terrestrial environments [17-19]. The reason is that different microbial ecological clusters often follow very specific environmental preferences. For example, taxa within some ecological clusters have been found to strongly correlate with low or high $\mathrm{pH}$, mesic or arid ecosystem, and nutrient availability and processes rates [15]. However, despite the importance of these ecological clusters for the understanding of the soil microbiome, their response to long-term field $\mathrm{Hg}$ pollution remains largely unexplored [20]. Increasing $\mathrm{Hg}$ concentrations could potentially impact the relative abundance of major ecological clusters with implications for ecosystem functioning. However, empirical evidence for such assumptions is currently lacking.

Moreover, the response of the functional attributes of the soil microbiome to $\mathrm{Hg}$ pollution has been rarely addressed. Such a task is challenging as soil microbial communities are highly diverse, and most soil microbial taxa remains uncharacterized [16, 21]. Recent advances in metagenomic sequencing can infer the functional traits of microbial communities $[22,23]$ and then determine which are sensitive to increased soil $\mathrm{Hg}$ pollution. We expect functional traits of soil microbial communities to follow predictable responses to $\mathrm{Hg}$ pollution. Such an expectation is based on the large body of literature reporting consistent microbial responses to other global changes such as climate change and nutrient additions [3, 23, 24].

Herein, we aimed to build a predictive understanding of the response of multiple soil taxonomic and functional attributes to increased $\mathrm{Hg}$ contents at the regional scale. Because $\mathrm{Hg}$ is a well-known pollutant with important implications for life on Earth [25], we hypothesized that soil $\mathrm{Hg}$ pollution will have consistent effects on taxonomic and functional attributes (e.g., relative abundance of functional genes) across different land use types. To do so, we collected three replicated soils at each of 47 sites (24 paddy fields and 23 adjacent upland fields), resulting in a total of 141 samples from Hg-impacted agricultural locations across two provinces in China. Most of the sites are surrounded by historical $\mathrm{Hg}$ mining areas with varying soil $\mathrm{Hg}$ contents, and their soils contained a wide range of $\mathrm{Hg}$ concentrations under similar vegetation types. These sites also included controls that are far away from the mining sites, with $\mathrm{Hg}$ contents similar to local background levels. As such, these locations provided a unique opportunity to empirically evaluate the response of microbial taxonomic and functional attributes to a gradient of soil $\mathrm{Hg}$ pollution. We characterized soil bacterial community composition via MiSeq Illumina platform. In addition, we investigated potential shifts in the relative abundance of functional genes linked to microbial communities by analyzing the soil metagenomes from a subset of those sites. Finally, we identified the associations between soil $\mathrm{Hg}$ concentrations and bacterial diversity, abundance, and ecological clusters (modules) using a combination of random forest analysis and structure equation modeling, after accounting for other critical environmental predictors.

\section{Results \\ Mercury pollution altered soil bacterial abundance and diversity}

We found a consistent decrease in the abundance of bacteria with increases in soil total $\mathrm{Hg}$ in both paddy and upland soils (Fig. 1a, b). Bacterial abundance was also negatively related to methylmercury $(\mathrm{MeHg})$ in paddy soils (d.f. $=1,70, P=0.008)$. In contrast, bacterial diversity (Shannon index) was positively correlated to total $\mathrm{Hg}$ (d.f. $=1,70, P=0.001$ ) in the paddy soils and tended to increase with elevated MeHg contents (d.f. $=1$, $70, P=0.08$ ) (Fig. 1c, d). We also found a cubic negative relationship (d.f. $=3,65, P=0.001$ ) between total $\mathrm{Hg}$ and bacterial diversity for the upland soils. As expected, land use type had significant effects on soil bacterial abundance and diversity (Additional file 1: Figure S1a, b), and both bacterial abundance and diversity were higher (ANOVA, d.f. $=1,139, P<0.05$ ) in paddy soils than those in upland soils.

\section{Mercury pollution altered the relative abundance of bacterial phyla}

We found consistent associations between of $\mathrm{Hg}$ contents and the relative abundance of some dominant bacterial phyla in both paddy and upland fields, though the bacterial community compositions were different between the two types of land use (Additional file 1: Figure S2). For example, increasing total $\mathrm{Hg}$ was positively related to the relative abundance of Firmicutes and Bacteroidetes in both paddy and upland soils (Fig. 2), while they were not related to MeHg. In contrast, increasing $\mathrm{MeHg}$ was negatively correlated to the relative abundance of Nitrospirae in the two soils, though it was not significantly correlated to soil total $\mathrm{Hg}(P>0.05)$. In addition, we found some correlations, depending on land use type, between total $\mathrm{Hg}$ / $\mathrm{MeHg}$ and the relative abundance of other dominant phyla/classes (Additional file 1: Table S1). Random forest analysis allowed us to further identify what genera of Firmicutes and Bacteroidetes were associated with increases in $\mathrm{Hg}$ contents (Additional file 1: Figure S3a, $P<0.05$ ). Thus, the relative abundance of Chitinophagaceae Ferruginibacter, Sphingobacteriaceae Pedobacter, and Clostridium 


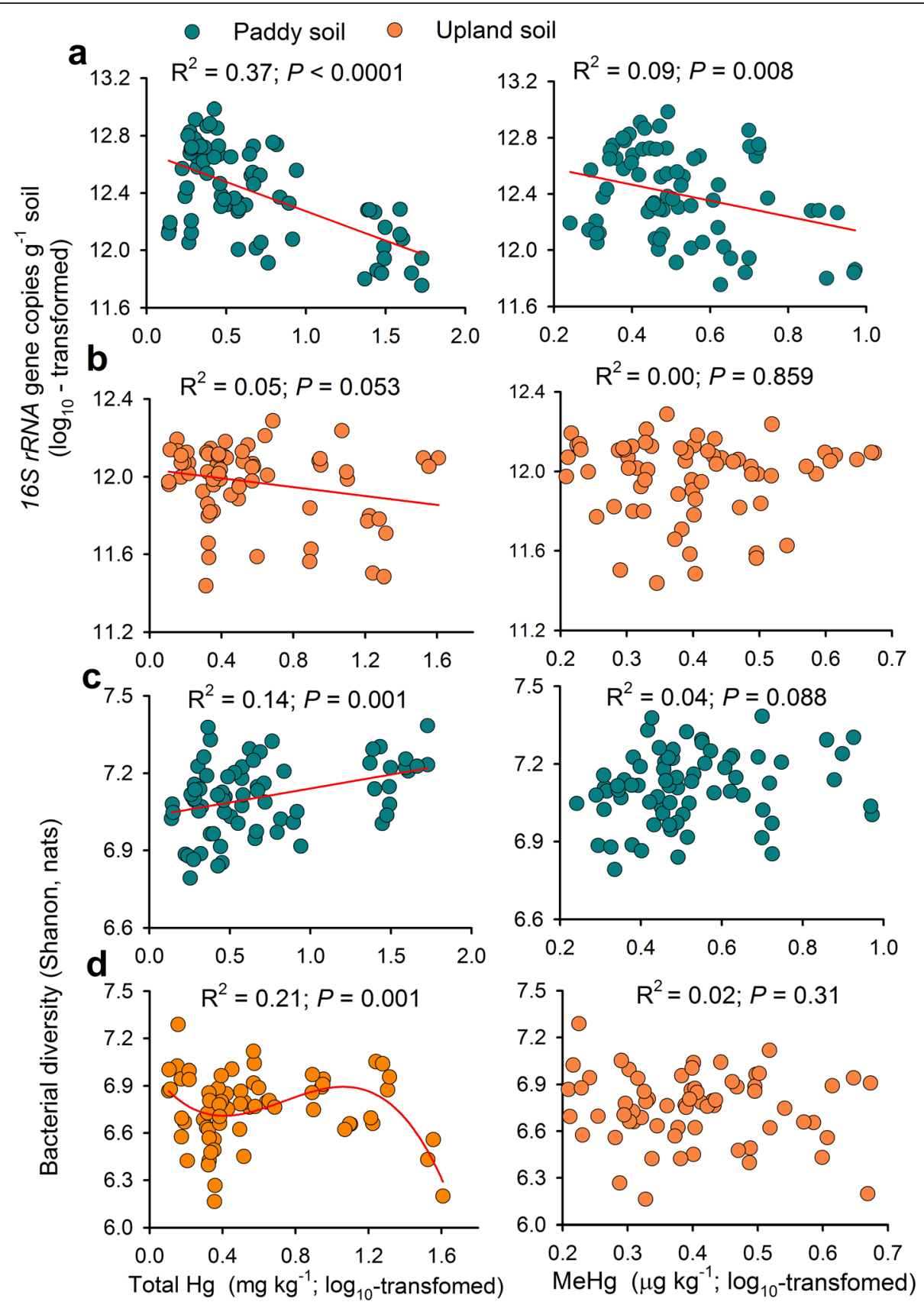

Fig. 1 Relationships between soil mercury ( $\mathrm{Hg}$, including total $\mathrm{Hg}$ and methylmercury, $\mathrm{MeHg}$ ) and the bacterial abundance (a, b), and diversity (c, d) in paddy and upland soils. Green and yellow dots represent samples from paddy and upland fields, respectively. Red lines represent regressions with linear (straight) and cubic (curve) functions $(P<0.05)$

sensu stricto_1 were positively correlated to soil total $\mathrm{Hg}$ (Additional file 1: Figure S3b, d.f. $=1,139, P<0.05$ ), while the relative abundance of Nitrospirae was negatively correlated to $\mathrm{MeHg}$ contents (Additional file 1: Figure S4, d.f. = $1,139, P<0.01)$.
Mercury pollution shifted the relative abundance of ecological clusters within the correlation network

The soil bacterial taxa could be grouped into five major ecological clusters (modules), comprised of strongly co-occurring bacterial taxa with one another (Fig. 3a). Not surprisingly, the two different soils were dominated by different ecological clusters in the two types of soil (Fig. 3b). Particularly, the relative abundance of module $\# 0$ was much higher (ANOVA, d.f. $=1,139, P<0.05$ ) in 


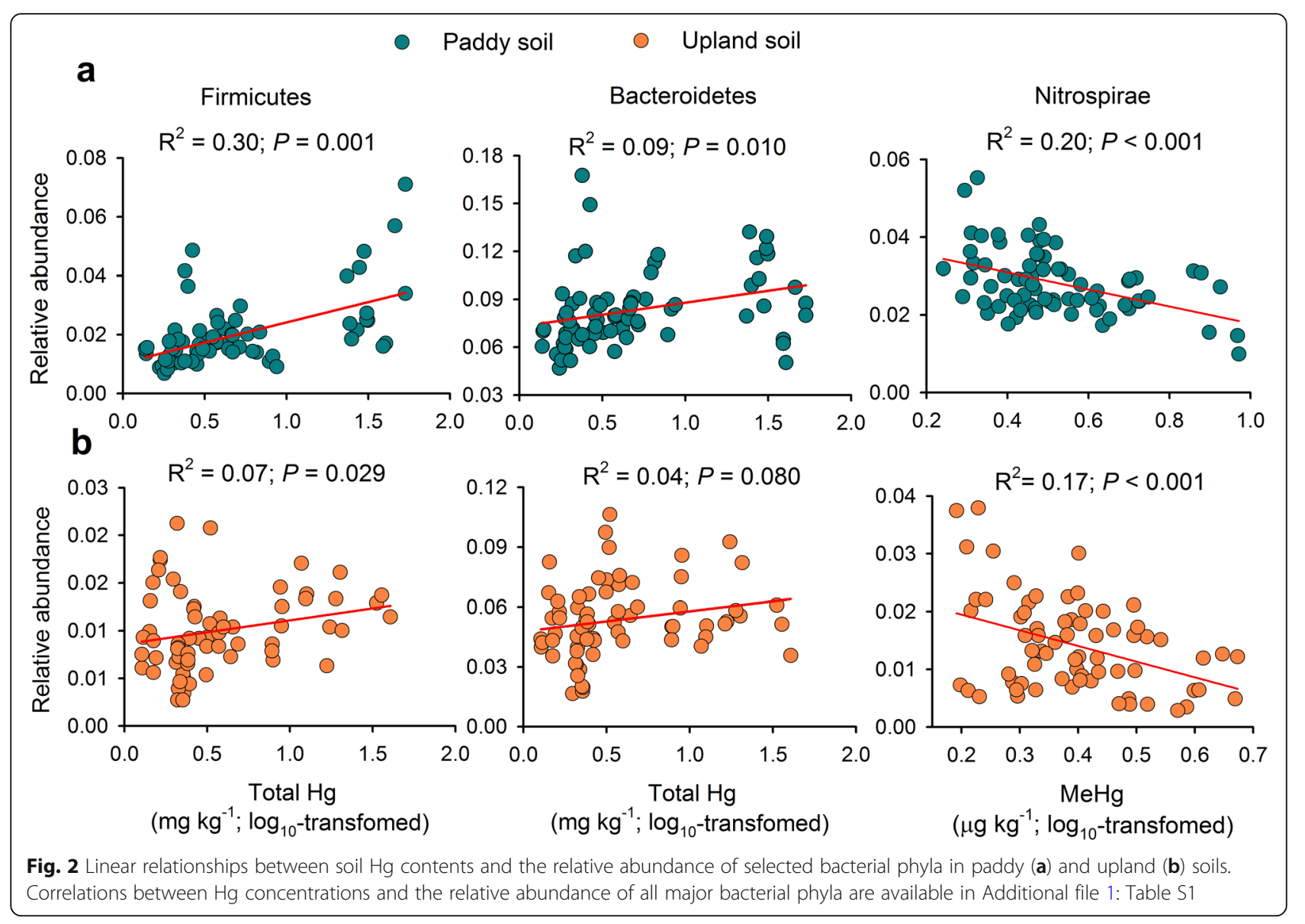

the paddy soils than that in the upland soils, while the relative abundance of module \#4 exhibited the opposite trend. Even so, we found consistent relationships between soil total $\mathrm{Hg} / \mathrm{MeHg}$ and the relative abundance of the dominant ecological clusters (Fig. 3c). For example, the relative abundance of module \#0 was negatively related to $\mathrm{MeHg}$ in both of soils, where the relative abundance of module \#4 was positively related to MeHg. All modules were formed by multiple phyla/classes, and the membership of each module is shown in Additional file 2 (data S1). We also found some soil-type-specific effects of $\mathrm{Hg}$ on the relative abundance of ecological clusters. For instance, the relative abundance of modules \#0 and \#4 decreased and increased, respectively, with increasing total $\mathrm{Hg}$ in the paddy soil (Fig. 3c), but no similar trends were observed in the upland soil. Meanwhile, the relative abundance of module \#2 and module \#3 decreased and increased, respectively, with increasing total $\mathrm{Hg}$ for the upland soil, while no similar response was observed for the paddy soil.
Mercury pollution is a significant predictor of soil bacterial community and ecological clusters after controlling for multiple environmental predictors

Random forest analysis suggested that, in general, $\mathrm{Hg}$ variables are major predictors of bacterial diversity and abundance (Additional file 1: Figure S5a, b) and the relative abundance of ecological clusters (Additional file 1: Figure S6a, b). As expected, our results indicate that other environmental factors were also important predictors of microbial communities, although the relative importance of these predictors was highly taxa and module dependent. See Additional file 1: Table S2 for correlations between microbial attributes and environmental predictors.

We then used structural equation modeling (SEM), to further clarify the role of $\mathrm{Hg}$ in predicting abundance, diversity, and the relative abundance of modules for both paddy and upland soils, after controlling for multiple other environmental predictors (Fig. 4a, b; Additional file 1: Table S3, S4). Remarkably, we found a consistent negative effect of total $\mathrm{Hg}$ on bacterial abundance in both soils. Our SEM shows direct effects of $\mathrm{MeHg}$ on the relative abundance of modules (Mod\#3 and Mod\#4) in upland soils and effects of total $\mathrm{Hg}$ and $\mathrm{MeHg}$ on the relative abundance of Mod\#1 in paddy soils. Interestingly, we 


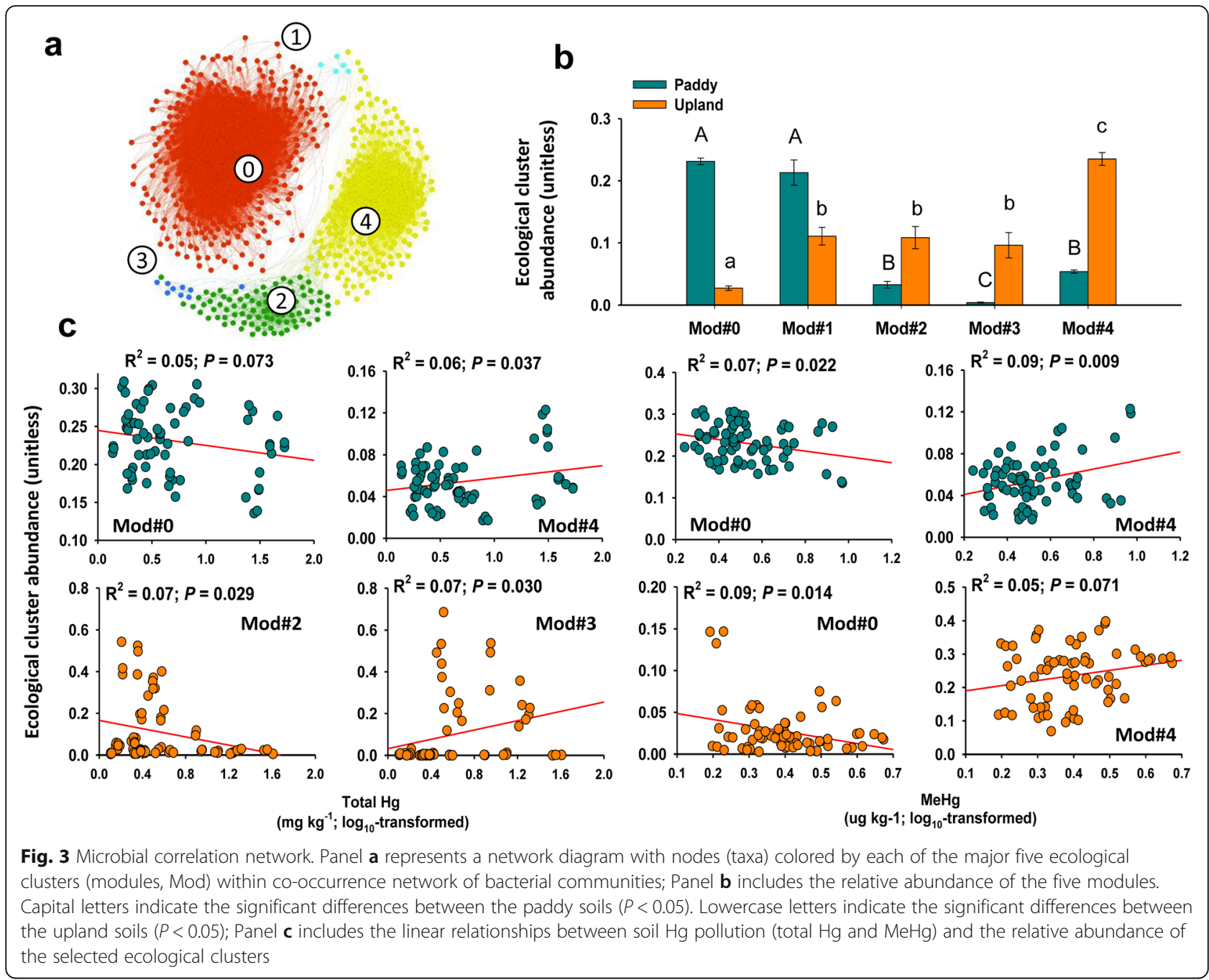

detected multiple indirect effects of $\mathrm{Hg}$ on the relative abundance of these modules via impacts on soil properties and other modules, though there may be interactions between these microbial attributes. The SEM also shows a direct effect of $\mathrm{Hg}$ on the bacterial diversity in upland soils, while the effect was not significant in the paddy soils. As expected, the SEM also shows strong effects of soil and spatial properties on these microbial attributes across the two types of land use.

\section{Functional gene relates to soil $\mathrm{Hg}$ pollution}

We conducted further random forest modeling to evaluate the link between functional genes and $\mathrm{Hg}$ pollution, and 22 functional genes that significantly predicted changes in total $\mathrm{Hg}$ across the soils were identified (Fig. 5a; Additional file 1: Table S5). Most of those genes are likely involved in soil nutrient metabolisms (e.g., reduction of nitrate and phosphate) and $\mathrm{Hg}$ transformations (e.g., $\mathrm{Hg}$ uptake and methylation). Furthermore, we found that the relative abundance of genes encoding member protein, diphosphate reductase, and dehydrogenase E1 component increased along elevated soil $\mathrm{Hg}$ contents, while the gene encoding 3-deoxy-D-manno-octulosonic-acid transferase accounting for glycan biosynthesis and metabolism, significantly decreased towards increased $\mathrm{Hg}$ (Fig. 5b). We also found 30 genes significantly predicting changes in soil $\mathrm{MeHg}$, including the genes involved in CoA synthetase and iron transport, that are important enzymes involved in $\mathrm{Hg}$ uptake and methylation (Additional file 1: Figure S7).

\section{Discussion}

Effects of $\mathrm{Hg}$ pollution on soil bacterial abundance and diversity in agricultural ecosystems

Both regression analysis and SEM demonstrate that long-term field $\mathrm{Hg}$ pollution had a negative effect on the bacterial abundance from the two land use types. Such a result is in contrast with a previous short-term incubation experiment where no effect of $\mathrm{Hg}$ pollution on bacterial abundance was found [13]. Both $\mathrm{Hg}$ and $\mathrm{MeHg}$ are toxic to life, and thus, long-term field $\mathrm{Hg}$ pollution may 


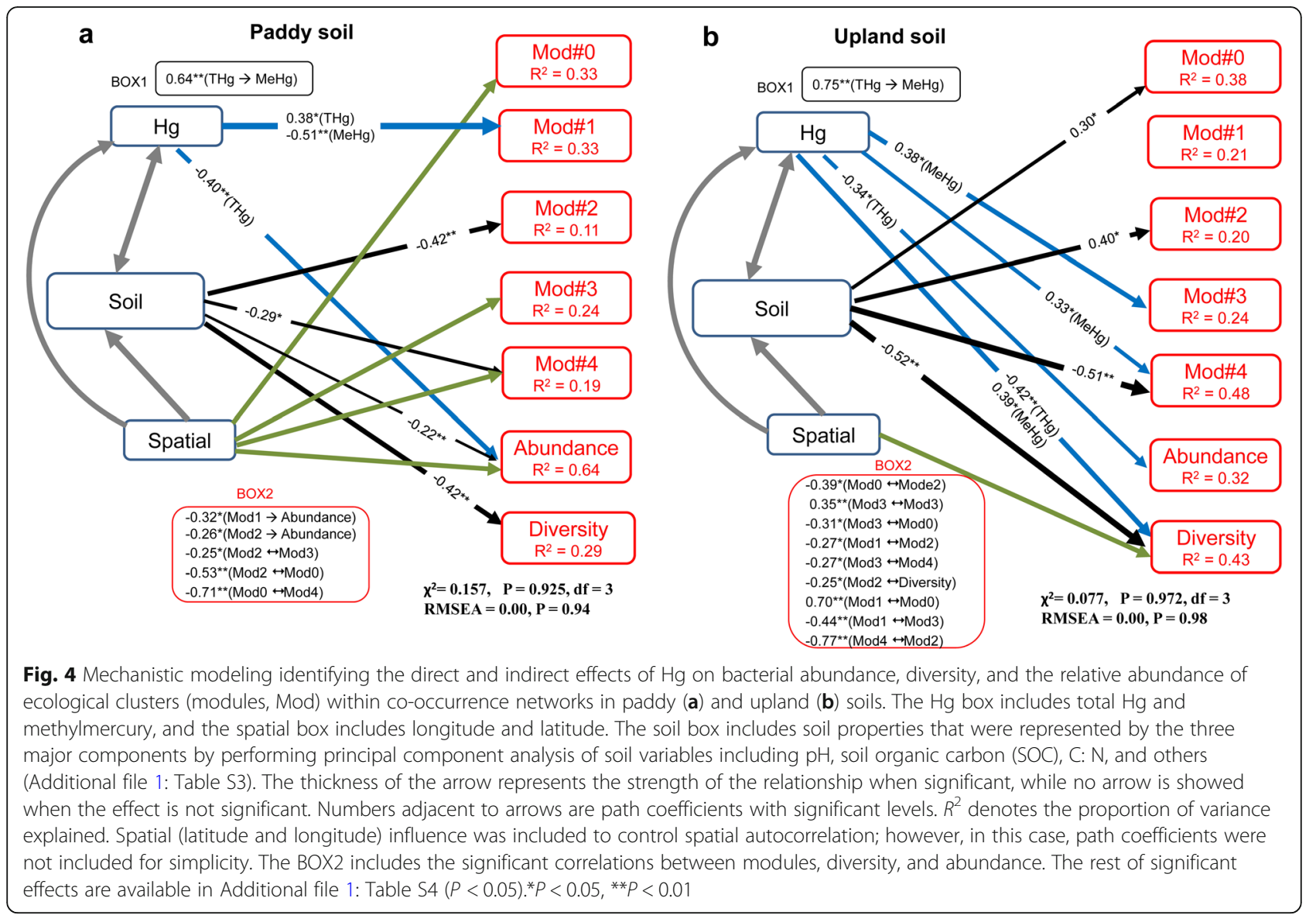

inhibit microbial growth and then cause a decrease in soil microbial abundance across centuries [8]. Importantly, the lack of an effect of $\mathrm{Hg}$ pollution on bacterial abundance in short-term experiments could be related to the fact that relic DNA from dead bacteria is also extracted and then quantified by qPCR [26, 27], obscuring the adverse effect of $\mathrm{Hg}$ on soil microbial abundance. Such an artifact should be largely diluted in long-term experiment and observational studies. Similarly, $\mathrm{MeHg}$ as the most toxic $\mathrm{Hg}$ speciation also negatively correlated to the bacterial abundance in the paddy soils, further emphasizing the strong effect of $\mathrm{Hg}$ pollution on bacterial abundance in soil. On the contrary, bacterial diversity tended to increase under moderate $\mathrm{Hg}$ content ( $<53 \mathrm{mg} \mathrm{kg}{ }^{-1}$, Fig. 1c), partially supporting the intermediate disturbance or stress hypothesis $[12,28]$. However, our observations are different from those from short-term incubation experiments, in which $\mathrm{Hg}$ amendment has been reported to reduce soil bacterial diversity [13]. As such, our approach suggests that large-scale observational studies are needed to understand the response of bacterial diversity to $\mathrm{Hg}$ pollution in real-world ecosystems. The soils examined in this study belong to Hg-mining areas which suffered serious $\mathrm{Hg}$ pollution for more than 600 years [29]. Consequently, the microbial community from these soils might have had time to develop resistance to $\mathrm{Hg}$ stress [13]. Alternatively, increasing $\mathrm{Hg}$ pollution might increase bacterial diversity by releasing subordinate microbial taxa via competition. These results are partially supported by our SEM suggesting a positive effect of $\mathrm{MeHg}$ on the diversity in upland soils, while the effect became complicated in paddy soils where no direct effect of total $\mathrm{Hg}$ or $\mathrm{MeHg}$ on the diversity was observed. However, $\mathrm{Hg}$ pollution may indirectly influence the bacterial diversity through impacts on soil properties, which were important drivers of soil microbial diversity [17, 21]. All of these observations illustrate the importance of $\mathrm{Hg}$ pollution in regulating the abundance and diversity of soil bacteria. Importantly, these results were maintained after accounting for multiple other drivers including soil and spatial properties.

\section{Mercury pollution altered soil bacterial community composition and the distribution of ecological clusters} Importantly, we also found that $\mathrm{Hg}$ pollution consistently related to the relative abundance of the dominant bacterial phyla. For example, the relative abundance of Firmicutes 
a
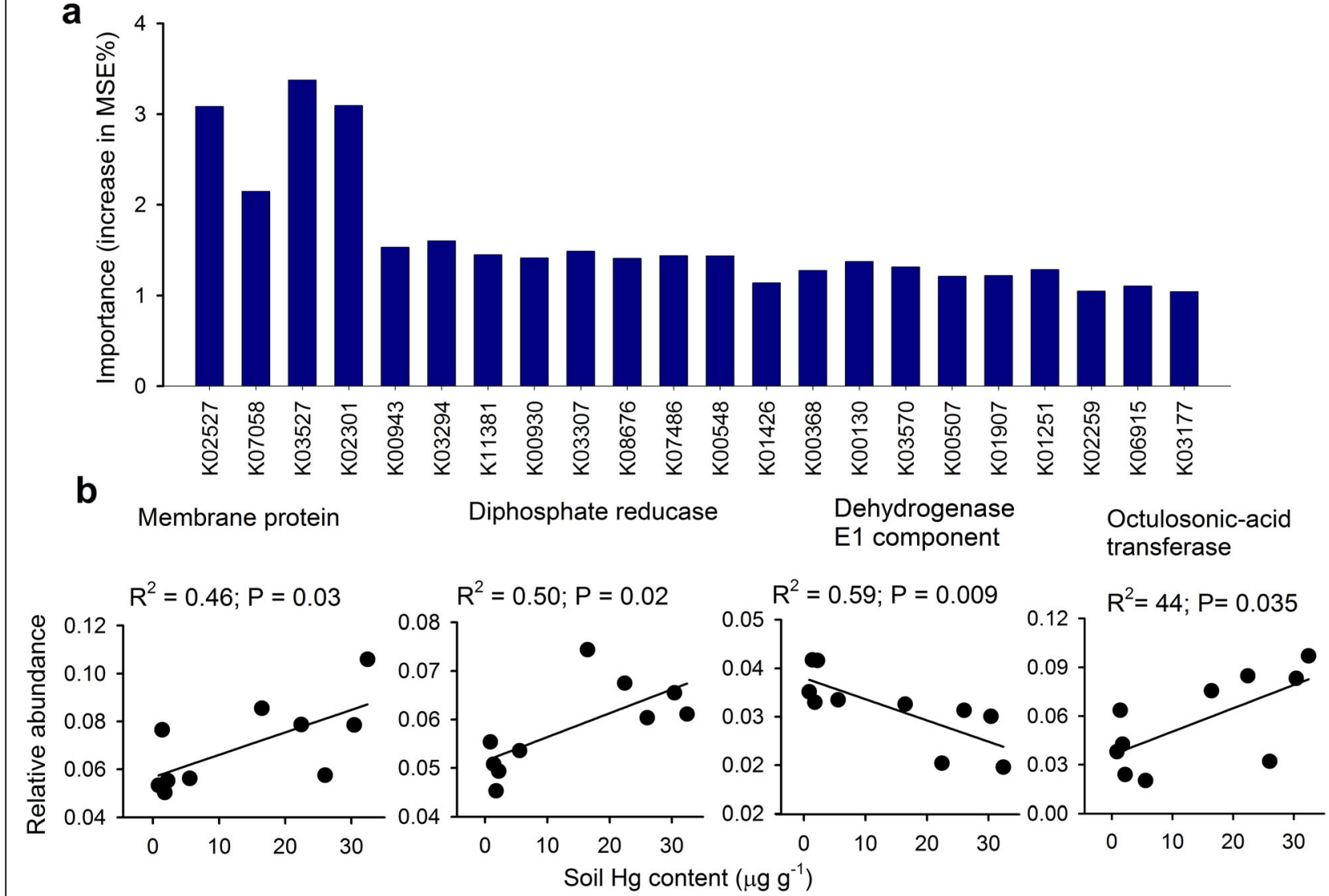

Fig. 5 Random forest (RF) analyses identifying the significant $(P<0.05)$ gene predictors of soil total Hg (a). Panel b includes relationships between total $\mathrm{Hg}$ contents and selected functional genes. These functional genes were annotated according to Kyoto Encyclopedia of Genes and Genomes (KEGG) using metagenomic data derived from a subset of our soil samples. Additional information on the KEGG genes is available in Additional file 1: Table S5

and Bacteroidetes increased in response to elevated total $\mathrm{Hg}$, but the relative abundance of Nitrospirae was negatively related to $\mathrm{MeHg}$ contents. Firmicutes and Bacteroidetes are known to be fast-growing opportunistic types of organisms that might benefit from environmental disturbance by taking over niches commonly occupied by other bacterial taxa. We also detected the genera of bacteria within these groups influenced by $\mathrm{Hg}$ pollutions (Additional file 1: Figure S3; Figure S4). For example, Sphingobacteriaceae Pedobacter and Clostridium sensu stricto have been reported to be resistant to $\mathrm{Hg}$ or heavy metals $[30,31]$; however, much less is known about the mechanisms linking the responses of Chitinophagaceae Ferruginibacter to $\mathrm{Hg}$ pollution. In addition, our large-scale data suggest a decrease in the relative abundance of Nitrospirae with elevated soil MeHg. Previous studies have found that this phylum is highly sensitive to heavy metal stress at the local scale $[12,32]$. The reduction in the relative abundance of Nitrospirae was mainly attributed to a relative decrease in the genus Nitrospirales 0319.6A21sp. in response to elevated MeHg. Increased
$\mathrm{Hg}$ pollution is known to inhibit the processes of nitrogen cycle driven by soil functional assembles [9, 33], which could be an important result of the inhibiting effect of $\mathrm{Hg}$ to nitrifying bacteria such as Nitrospirae. These results suggest that the sensitive taxa could be used as potential ecological indicators for $\mathrm{Hg}$ pollution in terrestrial ecosystems.

Our random forest analysis suggested that $\mathrm{Hg}$, in general, is a significant predictor of the ecologically preferential modules within the bacterial co-occurrence network after accounting for other key environmental predictors (Additional file 1: Figure S6). Thus, increases in soil $\mathrm{Hg}$ content also led to drastic changes in the co-occurrence network of soil bacterial communities in the studied regions. Interestingly, we found significant patterns of the relative abundances in some modules along increased $\mathrm{Hg}$ and MeHg pollution (Fig. 3c; Additional file 1: Table S6). For example, the relative abundance of module \#4 tended to increase with elevated total $\mathrm{Hg}$ and $\mathrm{MeHg}$ in both paddy and upland soils. This module mainly consisted of potentially Hg-resistant microbes such as Proteobacteria, 
Bacteroidetes, and Actinobacteria, which were reported to contain the Hg-resistance gene merA $[34,35]$. We also provide a list of winner (positive effects) and loser (negative effects) community assemblies in response to $\mathrm{Hg}$ pollution (Additional file 2: Data S1), which can be used to test for similarities in the response of soil microbial communities to $\mathrm{Hg}$ pollution worldwide.

Although SEM is quite a conservative procedure, the results support similar associations between $\mathrm{Hg}$ and the relative abundance of modules across the two types of land use. For example, soil $\mathrm{Hg}$ had direct effects on the relative abundance of module \#1 in paddy soils (Fig. 4a), and a similar effect on this module in upland soils could be reflected through indirect impacts of $\mathrm{Hg}$ on other modules (i.e., Mod\#2, Mod\#3, and Mod\#4) due to their interactions (Fig. 4b: BOX2). It is not surprising to note the interactions between the modules in the co-occurrence networks, because increases in a given ecological cluster were often followed by declines in the relative abundance of other ecological clusters [36]. These findings suggest that variability of $\mathrm{Hg}$ contents in the ecosystem might change the distributions of ecologically preferential clusters. Of course, as expected, other environmental predictors strongly associate with the relative abundance of microbial ecological clusters (Fig. 4, Additional file 1: Table S2; Additional file 1: Figure S6), which had been well recognized in many previous studies [15-17].

\section{Predicting soil $\mathrm{Hg}$ pollution from the variability of microbial functional genes}

We found that $\mathrm{Hg}$ pollution was also associated with important functional traits within microbial communities. In fact, here, we provide a list of functional genes which were strongly correlated to $\mathrm{Hg}$ contents across soils. Of course, we acknowledge the current limitations for linking genes to $\mathrm{Hg}$ pollution across large spatial scales due to the correlative nature of these analyses (Fig. 5; Additional file 1: Figure S7). Such results are in agreement with previous studies emphasizing significant effects of $\mathrm{Hg}$ stress on microbially driven processes (e.g., nitrification potential and dehydrogenase enzyme activity) driven by diverse soil microorganisms [9, 37]. For example, the relative abundance of genes involved in member protein tended to increase with the level of soil $\mathrm{Hg}$ pollution, suggesting that moderated $\mathrm{Hg}$ stress may stimulate the enzyme activities responsible for $\mathrm{Hg}$ transportation through the cell membrane [38]. We also observed a significant increase in the relative abundances of genes associated with dehydrogenase with elevated $\mathrm{Hg}$. These findings are consistent with those of previous studies showing upregulation of dehydrogenase activities exposed to metals [39]. In addition, we identified some genes that are relevant to $\mathrm{Hg}$ transport (i.e., iron transport system) and methylation processes (i.e., CoA synthetase) [40]. Previous studies has suggested that inorganic $\mathrm{Hg}(\mathrm{II})$ could be transported into microbial cells probably through ion transport system [41, 42], and the cellular $\mathrm{Hg}(\mathrm{II})$ is subsequent methylated to highly neurotoxic $\mathrm{MeHg}$ by methylating genes $h g c A B$ [43]. Thus, our predicted iron transport system might be relevant to soil $\mathrm{MeHg}$ formation. Furthermore, $\mathrm{Hg}$ methylation is an enzyme-catalyzed process associated with the reductive CoA pathway [44], which may explain our results that the $\mathrm{CoA}$ synthetase is a significant predictor for $\mathrm{MeHg}$ in the soil. Overall, these gene predictors are associated with nutrient metabolisms and $\mathrm{Hg}$ transformations, which are also important biomarkers of soil $\mathrm{Hg}$ pollution.

\section{Conclusions}

Together, our study represents one of the first attempts to empirically assess how the soil microbiomes respond to long-term $\mathrm{Hg}$ pollution across large spatial scales and land use type. We provides solid evidence that $\mathrm{Hg}$ pollution has predictable and significant effects on multiple taxonomic and functional microbial attributes including bacterial abundance, diversity, and the relative abundance of ecological clusters and functional genes. Such results are maintained after accounting for other important environmental predictors of soil microbial communities. In general, $\mathrm{Hg}$ pollution was negatively related to the bacterial abundance. The relative abundance of Bateroidetes and Firmicutes increased with elevated $\mathrm{Hg}$ pollution, while the relative abundance of Nitrospirae was negatively correlated to MeHg. Mercury-induced shifts in the ecological clusters of co-occurrence network and functional traits of microbial communities could have important implications for soil biogeochemical cycling and service functioning of the ecosystem. This work moves us towards a more predictable understanding of the response of microbial communities and their potential function to $\mathrm{Hg}$ pollution-a worldwide threat derived from both global warming and intensive anthropogenic activities.

\section{Methods}

\section{Study area and sampling}

The soil samples were collected around two typical $\mathrm{Hg}$ mining areas (Fenghuang, FH and Wanshan, WS) in southwest China. Fenghuang is located in West Hunan Province, and Wanshan in East Guizhou Province. Both of them are the major grain-producing areas in China, with a long history $\mathrm{Hg}$ mining for more than 600 years [29]. Historical discharges from $\mathrm{Hg}$ mining operations and ongoing atmospheric deposition has led to heavy $\mathrm{Hg}$ pollution in these areas [45]. We collected soil samples from 24 locations (Additional file 1: Figure S8) along downstream the mining sites to obtain samples with a large gradient of soil $\mathrm{Hg}$ concentrations (ranges from 
0.27 to $52.4 \mathrm{mg} \mathrm{kg}^{-1}$ ), and most of them were above risk control value for paddy soils in China $\left(0.6 \mathrm{mg} \mathrm{kg}^{-1}\right)$ [46]. Two typical types of land use including paddy fields (24 sub-sites) and adjacent uplands (23 sub-sites, maize planting) were chosen to compare the effects of land use on the microbial responses to long-term soil $\mathrm{Hg}$ pollution. We tried to choose locations where both paddy and upland fields are the main crop planting, and sporadic farmlands are excluded. Three replicated soil (0$15 \mathrm{~cm}$ depth) samples were collected at each of the 47 sites to account for small scale variation in $\mathrm{Hg}$ pollution. Consequently, a total of 141 soil samples were obtained from the 24 paddy (72 samples) and upland (69 samples) fields. These locations also included two control sites (paddy and adjacent upland fields) located in the natural reserve with little pollution (i.e., location no. 1 in Additional file 1: Figure S8). Total $\mathrm{Hg}$ concentrations in the control sites are similar the levels of local background values $\left(0.5 \sim 0.7 \mathrm{mg} \mathrm{kg}^{-1}\right)$, which are similar to the $\mathrm{Hg}$ risk control value for paddy soil in China [46]. We omitted an upland site due to the lack of representative field in the location. Sampling was conducted in August 2016 before harvesting. Collected soil samples were homogenized and sieved $(2.0 \mathrm{~mm})$ to get a representative microbial community [20, 47]. The sieved samples were subsequently divided into two sub-samples. One sub-sample was stored at $-20{ }^{\circ} \mathrm{C}$ for microbial analysis, while the other sub-sample was air-dried for the analysis of heavy metals and soil properties.

\section{Measurement of soil heavy metals and chemical indexes}

For $\mathrm{Hg}$ analysis, $0.20 \mathrm{~g}$ of each soil was digested with $10 \mathrm{~mL}$ mixed solution $\left(2 \mathrm{~mol} \mathrm{~L}^{-1} \mathrm{HNO}_{3}\right.$ and $4 \mathrm{~mol} \mathrm{~L}^{-1}$ $\mathrm{HCl}$ ) in a Teflon tube at $95{ }^{\circ} \mathrm{C}$ for $2 \mathrm{~h}$. The total amount of $\mathrm{Hg}$ in these extracts was determined via cold vapor atomic fluorescence spectrometry (CVAFS) [45], and the method detection limit was $0.2 \mathrm{ng} \mathrm{L}^{-1}$. For the analysis of other heavy metals (i.e., $\mathrm{Cu}, \mathrm{Pb}, \mathrm{Cd}, \mathrm{Zn}, \mathrm{Ni}$, and $\mathrm{As}$ ), $0.30 \mathrm{~g}$ soil were digested by trace mixed acids $(9.0 \mathrm{~mL}$ of $\mathrm{HNO}_{3}$ and $3.0 \mathrm{~mL}$ of $\mathrm{HF}$ ) in a MARS microwave digestion system (CEM, USA). The concentrations of the heavy metals in the final solution were measured using a 7700X Inductively Coupled Plasma-Mass Spectrometer (Agilent, USA). For $\mathrm{MeHg}, 0.40 \mathrm{~g}$ soil was used for $\mathrm{MeHg}$ extraction using $\mathrm{CuSO}_{4}$-methanol. The amount $\mathrm{MeHg}$ was determined using an automated $\mathrm{MeHg}$ analyzer (TEKRAN 2700 GC-CVAFS) [48]. Soil pH was determined on a fresh soil to water ratio of 1: 2.5 using a Delta $\mathrm{pH}$-meter. Soil organic carbon (SOC) was measured using the $\mathrm{K}_{2} \mathrm{CrO}_{7}$ oxidation titration method [49]. Total carbon (TC) and total nitrogen (TN) in soils were determined on a LECO TureMac Macro CN analyzer (LECO, St. Joseph, MI, USA). Dissolved organic carbon (DOC) in the soil was extracted with $0.5 \mathrm{M} \mathrm{K}_{2} \mathrm{SO}_{4}$ at a ratio of $1: 5$ by shaking at $200 \mathrm{rpm}$ for $1 \mathrm{~h}$ and filtering through a $0.45-\mu \mathrm{m}$ Millipore filter [50], and the DOC concentration was measured by a TOC analyzer (TOC-L Analyzer, Shimadzu, Japan). The ammonium and nitrate concentrations in the filtered extracts were analyzed within $24 \mathrm{~h}$ using a continuous flow analyzer (SAN++, Skalar, Breda, Holland).

\section{Analysis of soil bacterial communities through Illumina MiSeq sequencing}

The genomic DNA was isolated from $0.30 \mathrm{~g}$ of soil using the MoBio PowerSoil DNA Isolation Kit (QIAGEN Inc., USA) following the manufacturer's instructions. The abundance of bacteria was estimated by quantifying the 16S rRNA gene copy number on an iCycler iQ5 thermocycler (Bio-Rad, USA) using the primer pairs Eub338F/ Eub518R [51]. To evaluate the bacterial community composition, the V4 region of the bacterial $16 S$ rRNA gene was amplified using the primer pairs of $338 \mathrm{~F} / 806 \mathrm{R}$ [47]. The $50 \mu \mathrm{l}$ PCR reaction mixtures consisted of $25 \mu \mathrm{l}$ PremixTaq $^{\text {tix }}$ (Takara Biotechnology, Dalian, China), $1 \mu$ of each primer $(10 \mu \mathrm{M}), 3 \mu \mathrm{l}$ of template DNA, and $20 \mu \mathrm{l}$ of sterilized $\mathrm{ddH}_{2} \mathrm{O}$. The resultant PCR products were purified using the Wizard ${ }^{\circ}$ SV Gel and PCR Clean-Up System (Promega, San Luis Obispo, USA). The purified amplicons were equimolarly mixed, and $2 \times 250$ bp paired-end sequencing was carried out on an Illumina Miseq sequencer (Illumina Inc., San Diego, USA). Raw reads generated from the MiSeq paired-end sequencing were merged together using the Fast Length Adjustment of Short reads (FLASH). A chimera filtering approach UPARSE was employed as the Operational Taxonomic Unit (OTU or phylotype) picking strategy at $97 \%$ sequence similarity. We randomly selected an even number $(30,212)$ of reads from each sample to account for variability in sequencing depth before downstream analysis (Additional file 1: Figure S9). Representative sequences from individual OTUs generated in UPARSE were processed using the Quantitative Insights into Microbial Ecology (QIIME) pipeline. The bacterial diversity index was calculated based on $97 \%$ OTU similarity of obtained bacterial sequences. The taxonomic identity of all phylotypes was determined using The SILVA ribosomal RNA gene database project [52].

\section{Shotgun metagenomic sequencing and gene analysis}

Seven paddy soils and three upland soils were selected from our 141 samples for metagenomic analysis. These samples were chosen, after $\mathrm{Hg}$ analysis, to produce a wide range of $\mathrm{Hg}$ concentrations (ranged from 0.84 to $32.43 \mathrm{mg} \mathrm{kg}^{-1}$ ). Sequencing was performed using an Illumina PE150 (Illumina Inc.) at Majorbio, Inc., Shanghai, China. Raw reads (150 bp in length) were trimmed to remove low-quality reads. Paired reads of shotgun metagenomic sequences were merged with FLASH using default parameters [53]. Using 
MBLASTX, merged reads were also mapped against the protein sequence of the KEGG database ( $E$ value cutoff $\left.1 \mathrm{e}^{-6}\right)$, and the relative abundance of each $\mathrm{KO}$ gene was also calculated. Additional details on methodology are provided in the Additional file 3. To estimate the influence of elevated $\mathrm{Hg}$ and $\mathrm{MeHg}$ contents on these genes, we focused on the $\mathrm{KO}$ genes related to microbial metabolism, $\mathrm{Hg}$ transformations, and other sensitive ones.

\section{Correlation network analyses}

We established a co-occurrence network to identify ecological clusters of bacterial taxa across the collected 141 soil samples. A single correlation network including all samples was conducted so that the identified ecological clusters are directly comparable across land use types. We kept those taxa accounting for more than $80 \%$ of the relative abundance of soil bacteria (1073 bacterial taxa in Additional file 2: Data S1). We then calculated all pairwise Spearman's rank correlations $(\rho)$ between all soil bacterial taxa using the psych package of the $\mathrm{R}$ statistical software (http://cran.r-project.org/) and focused exclusively on positive correlations as they provide information on bacterial taxa that may respond similarly to environmental conditions [54]. We considered a co-occurrence to be robust if the Spearman's correlation coefficient was $>0.25$ and $P<0.01$ [17]. The network was visualized with the interactive platform Gephi [55]. Finally, we used default parameters from the interactive platform Gephi to identify ecological clusters (i.e., modules) of soil taxa strongly interacting with each other [55]. The relative abundance of each ecological cluster was computed by averaging the standardized relative abundances (z-score) of the taxa that belong to each ecological cluster [17].

\section{Statistical analysis}

We first identified the correlations between total $\mathrm{Hg}$ and $\mathrm{MeHg}$ with soil bacterial abundance, diversity (Shannon), and the relative abundance of ecological clusters in both paddy and upland soil, using linear or cubic models. We used both regression analyses and Pearson correlation to evaluate correlations between total $\mathrm{Hg}$ and $\mathrm{MeHg}$ and the relative abundance of ecological clusters, and bacterial community composition for two land use types using one ANOVA, with land use type as the fixed factor. We conducted a classification random forest analysis [56, 57] to identify the statistically significant predictors of the bacterial diversity, total abundance, and the relative abundance of ecological clusters. The major aim of these analyses were to test whether total $\mathrm{Hg}$ or $\mathrm{MeHg}$ pollution are significant predictors of microbial attributes, after accounting for other key environmental predictors including location, soil properties, heavy metals, and nutrient availability. We also used random forest analysis to identify the genus predictors of the phyla/classes that were significantly correlated to soil
$\mathrm{Hg}$. The random forest model determined the importance of each predictor variable via evaluating the decrease in prediction accuracy (i.e., increase in the mean square error between observations and $\mathrm{OOB}$ predictions) when the data for that predictor are randomly permuted, as previously described [58]. These analyses were conducted using the rfPermute package [59] of the R statistical software (http:// cran.r-project.org/). Additionally, we used Spearman's correlation analyses to further evaluate the correlations between bacterial diversity (Shannon), total abundance, and the relative abundance of ecological clusters with environmental predictors. We also used random forest analysis to identify the major functional genes predicting the concentrations of $\mathrm{Hg}$ and $\mathrm{MeHg}$ in our soils. In these analysis, functional genes are used as predictors of $\mathrm{Hg}$ concentrations. After this, we used linear regressions to evaluate the direction of the relationships between the relative abundance of selected genes and soil total Hg concentrations.

We then used structural equation modeling (SEM) [60] to further clarify associations of $\mathrm{Hg}$ (total $\mathrm{Hg}$ and $\mathrm{MeHg}$ ) contents with the bacterial abundance, diversity, and the relative abundance of ecological clusters (modules). Unlike the analysis of regression or ANOVA, SEM allows the ability to separate multiple effect pathways and consider them as parts of a system and thus is useful for isolating the complex relationships among environmental factors commonly found in natural ecosystems $[60,61]$. The probability that a path coefficient differs from zero was tested using bootstrap resampling. Bootstrapping is preferred to the classical maximum-likelihood estimation in these cases because in bootstrapping, probability assessments are not based on the assumption that the data match a particular theoretical distribution. Our model also includes spatial autocorrelation (latitude and longitude) and soil properties, which were represented by the three major components by performing principal component analysis of soil variables including $\mathrm{pH}$, soil organic carbon (SOC), $\mathrm{C}: \mathrm{N}$, and others (Additional file 1: Table S3). We first established an a priori model according to our current knowledge of environmental variable impacts on soil microbiomes (Additional file 1: Figure S10). The data matrix was fitted to the model using the maximum-likelihood estimation method. There is no single universally accepted test of overall goodness of fit for SEM. Thus, we used the chi-square test $\left(\chi^{2}\right.$; the model has a good fit when $0 \leq X^{2} /$ d.o.f $\leq 2$ and $\left.0.05<P \leq 1.00\right)$ and the root mean square error of approximation (RMSEA; the model has a good fit when RMSEA $0 \leq$ RMSEA $\leq 0.05$ and $0.10<$ $P \leq 1.00$ [62]. The SEM analyses were performed using AMOS 21.0 (SPSS Inc., Chicago, IL, USA). 


\section{Additional files}

Additional file 1: Table S1. Correlation coefficients (Pearson's $\rho$ ) between the dominant phyla/classes and soil $\mathrm{Hg}$ and $\mathrm{MeHg}$ contents. Table S2. Correlation coefficients (Spearman's $\rho$ ) between bacterial abundance, richness and modules, and soil properties. Table S3. Correlation coefficients (Spearman's $\rho$ ) between three major components from principal component analysis and soil properties. Table S4. Standardized direct effects from the SEM in Fig. 4. Table S5. The ID and names of the predicted functional genes (see Fig. 4) were annotated according to Kyoto Encyclopedia of Genes and Genomes (KEGG) using metagenomic data derived from a subset of our soil samples. Table S6. Correlation coefficients (Pearson's $\rho$ ) between bacterial modules (Mod) of co-occurrence network and soil $\mathrm{Hg}$ and MeHg contents.

Figure S1. Bacterial abundance and diversity in paddy and upland soils from Hg-impacted FH and WS areas in China Figure S2. Relative abundances of the dominant phyla (classes) based on MiSeq sequencing of 165 rRNA gene in paddy and upland soils. Figure S3. Predictor importance of main genera in Firmicutes and Bacteroideteses ponding to soil total $\mathrm{Hg}$ based on random forest analyses (a). Relationships between the predicted main species and soil total Hg (b). Figure S4. Relationship between the most important genus in Nitrospirare and soil MeHg. Figure S5. Random forest (RF) analyses identifying environmental predictors of soil bacterial abundance and diversity.

Figure S6. Random forest analyses identifying soil environmental predictors of the relative abundance of modules \#0-4 of bacterial occurrence network in paddy soils. Figure S7. Random forest analyses identifying the main significant gene predictors of soil total MeHg. Figure S8. Map of the study area and 24 sampling locations around the $\mathrm{Hg}$ mining area in southwest China. Figure S9. Rarefaction and Shannon curves of 165 rRNA gene sequencing of the soils. Figure S10. An a priori model identifying effects of Hg on soil microbiomes. (DOCX $1450 \mathrm{~kb}$ )

Additional file 2: Taxa composition of each module (ecological cluster). (XLSX $48 \mathrm{~kb}$ )

Additional file 3: Details regarding shotgun metagenomic sequencing and gene analysis. (DOCX $18 \mathrm{~kb}$ )

\section{Acknowledgements}

We thank Xinquan Zhou and Wenli Tang for their assistance in mercury analysis, and Pengpeng Xu for technical support in bioinformatics analysis. We gratefully acknowledge Chao Xiong and Anhui Ge for their assistance during field sampling. We thank Dr. PM Chalk (The University of Melbourne) for his language editing of this manuscript, and the anonymous reviewers for their constructive comments on this paper.

\section{Funding}

This research was supported in part by the National Natural Science Foundation of China (41877120, 41571453). M.D-B. acknowledges the support from the Marie Sklodowska-Curie Actions of the Horizon 2020 Framework Programme H2020-MSCA-IF-2016 under REA grant agreement no. 702057.

\section{Availability of data and materials}

The soil metagenomic dataset has been deposited to the NCBI Sequence Read Archive under accession number PRJNA450451.

\section{Authors' contributions}

YRL and MDB planned the research; YRL and LB conducted the laboratory analyses and collected the raw data. MDB and $Y R L$ analyzed the output data and performed all the statistical analyses; YRL, MDB, JZ, and JZH wrote the first draft of the manuscript, and all authors contributed to revisions. All authors read and approved the final manuscript

\section{Ethics approval and consent to participate}

Not applicable.

\section{Consent for publication}

Not applicable.

\section{Competing interests}

The authors declare that they have no competing interests.

\section{Publisher's Note}

Springer Nature remains neutral with regard to jurisdictional claims in published maps and institutional affiliations.

\section{Author details}

${ }^{1}$ State Key Laboratory of Agricultural Microbiology, Huazhong Agricultural University, Wuhan 430070, People's Republic of China. 'State Key Laboratory of Urban and Regional Ecology, Research Center for Eco-Environmental Sciences, Chinese Academy of Sciences, Beijing 100085, China. ${ }^{3}$ College of Resources and Environment, Huazhong Agricultural University, Wuhan 430070, China. ${ }^{4}$ Cooperative Institute for Research in Environmental Sciences, University of Colorado, Boulder, CO 80309, USA. ${ }^{5}$ Departamento de Biología, Geología, Física y Química Inorgánica, Escuela Superior de Ciencias Experimentales y Tecnología, Universidad Rey Juan Carlos, c/Tulipán s/n, 28933 Móstoles, Spain. ${ }^{6}$ Faculty of Veterinary and Agricultural Sciences, The University of Melbourne, Parkville, Victoria 3010, Australia.

Received: 5 July 2018 Accepted: 8 October 2018

Published online: 18 October 2018

\section{References}

1. Bissett A, Brown MV, Siciliano SD, Thrall PH. Microbial community responses to anthropogenically induced environmental change: towards a systems approach. Ecol Lett. 2013;16:128-39.

2. Griffiths BS, Philippot L. Insights into the resistance and resilience of the soil microbial community. FEMS Microbiol Rev. 2013;37(2):112-29.

3. Jiao S, Zhang Z, Yang F, Lin Y, Chen W, Wei G. Temporal dynamics of microbial communities in microcosms in response to pollutants. Mol Ecol. 2017;26(3):923-36.

4. Alava JJ, Cheung WWL, Ross PS, Sumaila UR. Climate change-contaminant interactions in marine food webs: toward a conceptual framework. Glob Chang Biol. 2017;23(10):3984-4001.

5. Obrist D, Agnan Y, Jiskra M, Olson CL, Colegrove DP, Hueber J, Moore CW, Sonke JE, Helmig D. Tundra uptake of atmospheric elemental mercury drives Arctic mercury pollution. Nature. 2017;547(7662):201-4.

6. Schuster PF, Schaefer KM, Aiken GR, Antweiler RC, Dewild JF, Gryziec JD, Gusmeroli A, Hugelius G, Jafarov E, Krabbenhoft DP, et al. Permafrost stores a globally significant amount of mercury. Geophysl Res Lett. 2018;45(3): 1463-71.

7. Krabbenhoft DP, Sunderland EM. Global change and mercury. Science. 2013; 341(6153):1457-8.

8. Mahbub KR, Krishnan K, Naidu R, Andrews S, Megharaj M. Mercury toxicity to terrestrial biota. Ecol Indic. 2017;74:451-62.

9. Liu Y-R, Zheng Y-M, Shen J-P, Zhang L-M, He J-Z. Effects of mercury on the activity and community composition of soil ammonia oxidizers. Environ Sci Pollut Res. 2010;17(6):1237-44.

10. Müller AK, Westergaard K, Christensen S, Sørensen SJ. The effect of longterm mercury pollution on the soil microbial community. FEMS Microbiol Ecol. 2001;36(1):11-9.

11. Harris-Hellal J, Vallaeys T, Garnier-Zarli E, Bousserrhine N. Effects of mercury on soil microbial communities in tropical soils of French Guyana. Appl Soil Ecol. 2009:41(1):59-68.

12. Liu Y-R, Wang J-J, Zheng Y-M, Zhang L-M, He J-Z. Patterns of bacterial diversity along a long-term mercury-contaminated gradient in the paddy soils. Microb Ecol. 2014;68(3):575-83.

13. Frossard A, Hartmann M, Frey B. Tolerance of the forest soil microbiome to increasing mercury concentrations. Soil Biol Biochem. 2017;105:162-76.

14. Frey B, Rieder SR. Response of forest soil bacterial communities to mercury chloride application. Soil Biol Biochem. 2013;65:329-37.

15. Menezes AB, Prendergast-Miller MT, Richardson AE, Toscas P, Farrell M, Macdonald LM, Baker G, Wark T, Thrall PH. Network analysis reveals that bacteria and fungi form modules that correlate independently with soil parameters. Environ Microbiol. 2015;17(8):2677-89.

16. Delgado-Baquerizo M, Oliverio AM, Brewer TE, Benavent-González A, Eldridge DJ, Bardgett RD, Maestre FT, Singh BK, Fierer N. A global atlas of the dominant bacteria found in soil. Science. 2018;359(6373):320-5.

17. Delgado-Baquerizo M, Reith F, Dennis PG, Hamonts K, Powell JR, Young A Singh BK, Bissett A. Ecological drivers of soil microbial diversity and soil biological networks in the Southern Hemisphere. Ecology. 2018;99(3):583-96. 
18. Van Der Heijden MGA, Bardgett RD, Van Straalen NM. The unseen majority: soil microbes as drivers of plant diversity and productivity in terrestrial ecosystems. Ecol Lett. 2008;11(3):296-310.

19. Shi $Y$, Li Y, Xiang $X$, Sun $R$, Yang $T$, He D, Zhang $K$, Ni $Y$, Zhu Y-G, Adams JM, et al. Spatial scale affects the relative role of stochasticity versus determinism in soil bacterial communities in wheat fields across the North China Plain. Microbiome. 2018;6(1):27.

20. Frossard A, Donhauser J, Mestrot A, Gygax S, Bååth E, Frey B. Long- and short-term effects of mercury pollution on the soil microbiome. Soil Biol Biochem. 2018;120:191-9.

21. Fierer N. Embracing the unknown: disentangling the complexities of the soil microbiome. Nat Rev Micro. 2017;15(10):579.

22. Zhang X, Johnston ER, Barberán A, Ren Y, Lü X, Han X. Decreased plant productivity resulting from plant group removal experiment constrains soil microbial functional diversity. Glob Chang Biol. 2017;23(10):4318-32.

23. Leff JW, Jones SE, Prober SM, Barberán A, Borer ET, Firn JL, Harpole WS, Hobbie SE, Hofmockel KS, Knops JMH, et al. Consistent responses of soil microbial communities to elevated nutrient inputs in grasslands across the globe. Proc Natl Acad Sci U S A. 2015;112(35):10967-72.

24. Zhang X, Johnston ER, Li L, Konstantinidis KT, Han X. Experimental warming reveals positive feedbacks to climate change in the Eurasian Steppe. ISME J. 2017;11(4):885-95.

25. Obrist D, Kirk JL, Zhang L, Sunderland EM, Jiskra M, Selin NE. A review of global environmental mercury processes in response to human and natural perturbations: changes of emissions, climate, and land use. Ambio. 2018; 47(2):116-40.

26. Frostegård $\AA$, Courtois S, Ramisse V, Clerc S, Bernillon D, Le Gall F, Jeannin P, Nesme $X$, Simonet P. Quantification of bias related to the extraction of DNA directly from soils. Appl Environ Microbiol. 1999;65(12):5409-20.

27. Carini P, Marsden PJ, Leff JW, Morgan EE, Strickland MS, Fierer N. Relic DNA is abundant in soil and obscures estimates of soil microbial diversity. Nat Microbiol. 2017;2:16242.

28. Connell JH. Diversity in tropical rain forests and coral reefs. Science. 1978; 199(4335):1302-10

29. Feng X, Li P, Qiu G, Wang S, Li G, Shang L, Meng B, Jiang H, Bai W, Li Z, et al. Human exposure to methylmercury through rice intake in mercury mining areas, Guizhou Province, China. Environ Sci Technol. 2008;42(1):326-32.

30. Lee J, Jung Y-J, Lee HK, Hong SG, Kim O-S. Complete genome sequence of Pedobacter cryoconitis PAMC 27485, a CRISPR-Cas system-containing psychrophile isolated from Antarctica. J Biotechnol. 2016;226:74-5.

31. Wu S, Li Y, Wang P, Zhong L, Qiu L, Chen J. Shifts of microbial community structure in soils of a photovoltaic plant observed using tag-encoded pyrosequencing of 16S rRNA. Appl Microbiol Biotechnol. 2016;100:3735-45.

32. Das S, Jean J-S, Kar S, Liu C-C. Changes in bacterial community structure and abundance in agricultural soils under varying levels of arsenic contamination. Geomicrobiol J. 2013;30(7):635-44.

33. Zhou Z, Zheng Y, Shen J, Zhang L, Liu Y, He J. Responses of activities, abundances and community structures of soil denitrifiers to short-term mercury stress. J Environm Sci. 2012;24(3):369-75.

34. Barkay T, Miller SM, Summers AO. FEMS Microbiol Rev. 2003;27:355-84.

35. Møller AK, Barkay T, Hansen MA, Norman A, Hansen LH, Sørensen SJ, Boyd ES, Kroer N. Mercuric reductase genes (merA) and mercury resistance plasmids in high Arctic snow, freshwater and sea-ice brine. FEMS Microbio Ecol. 2014:87(1):52-63.

36. Delgado-Baquerizo M, Eldridge David J, Travers Samantha K, Val J, Oliver I, Bissett A. Effects of climate legacies on above- and belowground community assembly. Glob Chang Biol. 2018;24:4330-9.

37. Mahbub KR, Krishnan K, Megharaj M, Naidu R. Mercury inhibits soil enzyme activity in a lower concentration than the guideline value. Bull Environ Contam Toxicol. 2016;96(1):76-82.

38. Barkay T, Wagner-Dobler I. Microbial transformations of mercury: potentials, challenges, and achievements in controlling mercury toxicity in the environment. Adv Appl Microbiol. 2005;57:1):1-52.

39. Lim JC, Thevarajoo S, Selvaratnam C, Goh KM, Shamsir MS, Ibrahim Z, Chong CS. Global transcriptomic response of Anoxybacillus sp. SK 3-4 to aluminum exposure. J Basic Microbiol. 2017;57(2):151-61.

40. Hsu-Kim H, Kucharzyk KH, Zhang T, Deshusses MA. Mechanisms regulating mercury bioavailability for methylating microorganisms in the aquatic environment: a critical review. Environ Sci Technol. 2013;47(6):2441-56.
41. Szczuka A, Morel FMM, Schaefer JK. The effect of thiols, zinc, and redox conditions on Hg uptake in Shewanella oneidensis. Environ Sci Technol. 2015;49(12):7432-8.

42. Schaefer JK, Rocks SS, Zheng W, Liang L, Gu B, Morel FMM. Active transport, substrate specificity, and methylation of $\mathrm{Hg}(\mathrm{II})$ in anaerobic bacteria. Proc Natl Acad Sci U S A. 2011;108(21):8714-9.

43. Parks JM, Johs A, Podar M, Bridou R, Hurt RA, Smith SD, Tomanicek SJ, Qian $Y$, Brown SD, Brandt CC, et al. The genetic basis for bacterial mercury methylation. Science. 2013;339(6125):1332-5.

44. Choi S-C, Chase T, Bartha R. Metabolic pathways leading to mercury methylation in Desulfovibrio desulfuricans LS. Appl Environ Microbiol. 1994; 60(11):4072-7

45. Meng M, Li B, Shao J-J, Wang T, He B, Shi J-J, Ye Z-H, Jiang G-B. Accumulation of total mercury and methylmercury in rice plants collected from different mining areas in China. Environ Pollut. 2014;184:179-86.

46. Ministry of Ecology and Environment of the People's Republic of China. Soil environmental quality, risk control standard for soil contamination of agricultural land (GB 15618-2018), 2018. (in Chinese).

47. Delgado-Baquerizo M, Maestre FT, Reich PB, Jeffries TC, Gaitan JJ, Encinar D, Berdugo M, Campbell CD, Singh BK. Microbial diversity drives multifunctionality in terrestrial ecosystems. Nat Commun. 2016;7:10541.

48. Liu Y-R, Dong J-X, Zhang Q-G, Wang J-T, Han L-L, Zeng J, He J-Z. Longitudinal occurrence of methylmercury in terrestrial ecosystems of the Tibetan Plateau. Environ Pollut. 2016;218:1342-9.

49. Walkley A, Black IA. An examination of the Degtjareff method for determining soil organic matter, and a proposed modification of the chromic acid titration method. Soil Sci. 1934;37(1):29-38.

50. Jones DL, Willett VB. Experimental evaluation of methods to quantify dissolved organic nitrogen (DON) and dissolved organic carbon (DOC) in soil. Soil Biol Biochem. 2006;38(5):991-9.

51. Cregger MA, Schadt CW, McDowell NG, Pockman WT, Classen AT. Response of the soil microbial community to changes in precipitation in a semiarid ecosystem. Appl Environ Microbiol. 2012;78(24):8587-94.

52. Quast C, Pruesse E, Yilmaz P, Gerken J, Schweer T, Yarza P, Peplies J, Glöckner FO. The SILVA ribosomal RNA gene database project: improved data processing and web-based tools. Nucleic Acids Res. 2013;41(D1):D590-6.

53. Magoč T, Salzberg SL. FLASH: fast length adjustment of short reads to improve genome assemblies. Bioinformatics. 2011;27(21):2957-63.

54. Barberán A, Casamayor EO, Fierer N. The microbial contribution to macroecology. Front Microbiol. 2014;5:203.

55. Bastian M, Heymann S, Jacomy M: Gephi: an open source software for exploring and manipulating networks; 2009.

56. Breiman L. Random forests. Mach Learn. 2001;45(1):5-32.

57. Trivedi P, Delgado-Baquerizo M, Trivedi C, Hu H-W, Anderson I-C, Jeffries TC, Zhou J, Singh B. Microbial regulation of the soil carbon cycle: evidence from gene-enzyme relationships. ISME J. 2016;10:2593-604.

58. Delgado-Baquerizo M, Gallardo A, Covelo F, Prado-Comesaña A, Ochoa V, Maestre FT. Differences in thallus chemistry are related to species-specific effects of biocrust-forming lichens on soil nutrients and microbial communities. Funct Ecol. 2015;29:1087-98.

59. Archer E. rfPermute, Estimate permutation p-values for random forest importance metrics. R package version 1.5.2. 2016.

60. Grace JB. Structural equation modeling and natural systems. Cambridge: Cambridge University Press; 2016.

61. Maestre FT, Quero JL, Gotelli NJ, Escudero A, Ochoa V, Delgado-Baquerizo M, García-Gómez M, Bowker MA, Soliveres S, Escolar C. Plant species richness and ecosystem multifunctionality in global drylands. Science. 2012;335:214-8.

62. Jing X, Sanders NJ, Shi Y, Chu H, Classen AT, Zhao K, Chen L, Shi Y, Jiang Y, He $J$ J. The links between ecosystem multifunctionality and above- and belowground biodiversity are mediated by climate. Nat Commun. 2015;6:8159. 